\title{
Seasonal Differences of Psychological and Physiological Responses in Tropical Urban Climate
}

\author{
Yoshihito Kurazumi $^{1}$, Jin Ishii ${ }^{2}$, Kenta Fukagawa ${ }^{3}$, Emi Kondo ${ }^{4}$, Agnes Nyilas ${ }^{1}$, Ariya Aruninta ${ }^{5}$ \\ ${ }^{1}$ School of Life Studies, Sugiyama Jogakuen University, Nagoya, Japan \\ ${ }^{2}$ Department of Architecture, Meijo University, Nagoya, Japan \\ ${ }^{3}$ Department of Architecture, Kyushu Sangyo University, Fukuoka, Japan \\ ${ }^{4}$ Department of Architecture, Ariake National College of Technology, Omuta, Japan \\ ${ }^{5}$ Department of Landscape Architecture, Chulalongkorn University, Bangkok, Thailand \\ Email: *kurazumi@sugiyama-u.ac.jp
}

How to cite this paper: Kurazumi, Y., Ishii, J., Fukagawa, K., Kondo, E., Nyilas, A. and Aruninta, A. (2017) Seasonal Differences of Psychological and Physiological Responses in Tropical Urban Climate. Health, 9, 896-920.

https://doi.org/10.4236/health.2017.96064

Received: March 1, 2017

Accepted: June 11, 2017

Published: June 14, 2017

Copyright (c) 2017 by authors and Scientific Research Publishing Inc. This work is licensed under the Creative Commons Attribution International License (CC BY 4.0).

http://creativecommons.org/licenses/by/4.0/

\section{Abstract}

This research aims to use the outdoor thermal environment evaluation index ETFe to quantify effects on the thermal sense of the human body of a tropical region climate with small annual temperature differences, and to examine seasonal differences in the thermal sense. Given that the average temperature of the earth is forecasted to rise, studying the effects on the human body from outdoor thermal environments in tropical regions is important for considering how to spend time outdoors in the future. This study clarifies seasonal differences in effects on the human body by comparing the effects on the thermal sensations of the human body from outdoor thermal environments in the winter and the dry season of Bangkok, Thailand in the tropics. The mobile measurements were carried out on the campus of Chulalongkorn University, Bangkok, Thailand. The subjects reported the thermal sensation and the thermal comfort that they experienced while exposed at the observation point. Air temperature, humidity, air velocity, short-wave solar radiation, long-wave thermal radiation, ground surface temperature, sky factor and the ratio of green and water surface solid angles were measured. We found no large seasonal difference between the winter and the dry season in skin temperature due to body temperature regulation. It is clear that in the winter season, people prefer a lower temperature than in the dry season, and in the dry season they tolerate higher temperatures than in winter. The effect of the seasonal difference appears in the amount of change to thermal sensation. We found that it is difficult for seasonal differences to greatly affect the amount of change to thermal comfort. We found that the effect of seasonal difference is that people show stronger responses to thermal comfort for thermal sensation 
in winter than in the dry season.

\section{Keywords}

ETFe, Outdoor, Seasonal Difference, Thermal Sense, Tropical Climate

\section{Introduction}

Irreparable damage due to climate change, such as the drought, abnormal weather, rise in sea levels, expansion of infectious diseases, and extinction of species, is steadily spreading throughout the world.

The Paris Agreement, a new international legal framework for greenhouse gas reduction, was adopted in December 2015 at the 21 st Conference of Parties to the Framework Convention on Climate Change (COP 21) [1]. In order to reduce the serious effects due to climate change, countries throughout the world are aiming for a global consensus to keep the average temperature rise to less than $2{ }^{\circ} \mathrm{C}$ compared to the era before the Industrial Revolution. This agreement also states that holding the average temperature rise to less than $1.5^{\circ} \mathrm{C}$ greatly contributes to reducing the risk.

This situation is affected by the Fifth Assessment Report of the Intergovernmental Panel on Climate Change (IPCC) in April 2014 [2]. If no actions are taken to reduce greenhouse gas emissions, the average temperature of the earth is likely to rise by $3.7^{\circ} \mathrm{C}$ to $4.8^{\circ} \mathrm{C}$ compared to the era before the Industrial Revolution, indicating the possibility of poor outdoor thermal environments. Areas with moderate thermal environments would transform into tropical areas, and there is a possibility that those areas will have smaller annual temperature differences. In other words, changes in the four seasons could become less dramatic, with smaller seasonal changes. Physiological functions of the human body are affected by annual temperature differences and nutrition intake ratios, etc., which climate change also affects. In particular, seasonal variation in basal metabolism has been found [3].

Thermal sensation affects body temperature regulation. As a starting point for behavioral body temperature regulation (environmental shelter behavior) taken to improve from a poor thermal environment to a more pleasant environment, thermal sensation (hot/cold sensation and thermal comfort, etc.) of a thermal environment stimulus is important. A decrease in the autonomous body temperature regulation function leads to changes in deep temperature. Delay in environmental shelter behavior occurs when there is a delay or dullness in the thermal sensation reaction to heat and the body's overheating. In order to prevent health damage, it is essential to clarify the effects of body temperature's control load on the human body.

In experiments on the effects of the thermal environment on the human body, research dealing with seasonal variation has conducted experiments in a steady state and an unsteady state. Experiments in an indoor environment in a steady 
state have found that there is no clear seasonal difference between the optimum temperature and the thermal neutral temperature when the thermal environmental conditions are the same [4]-[10] and they also show that even in experiments in an indoor environment in a steady state, the thermal neutral temperature is lower in winter than in summer, with a seasonal difference in thermal sensation. However, due to experiments under different clothing conditions according to the season, it cannot necessarily be concluded that deviation of thermal sensation is an effect due to seasonal difference.

Experiments in an indoor environment in an unsteady state show that thermal sensation is more strongly affected in summer than in winter, and there is a seasonal difference in thermal sensation [11] [12]. However, those experimental procedures did not isolate environmental history, so it is inferred that these effects appear as a seasonal difference. In these studies, only the temperature is compared with the seasonal difference. In an environment in an unsteady state, the magnitude of the heat capacity of the indoor component surfaces affects the time constant of the change of surface temperatures. Therefore, the heat balance between the human body and the environment may be affected by differences in temperature and long-wavelength thermal radiation, and differences in clothing. However, effects on the human body are not compared with the thermal environment evaluation index based on the heat balance of the human body.

Surveys on the effects of the thermal environment on the human body have been conducted to measure the influence of the human body in an indoor environment and an outdoor environment in an unsteady state. Actual measurements in an indoor environment in an unsteady state showed that the thermal neutral temperature is higher in summer than in winter, and there is a seasonal difference in thermal sensation [13] [14] [15] [16]. These were real-life surveys, so one can infer that effects of clothing and environmental history appeared as seasonal differences.

In actual measurements in outdoor environments that are in an unsteady state, thermal adaptation results in a thermal sensation different from the indoor environment. In winter, people prefer a lower temperature than in summer, and tolerate higher temperatures in summer than in winter [17]-[24]. As in surveys of indoor environments, it is inferred that effects of clothing and environmental history appear as seasonal differences. In addition, in these studies, thermal comfort was targeted at a nonspecific overall comfort feeling rather than a thermally unique pleasant sensation. Therefore, it was considered to be thermal comfort, but it cannot be denied that it was a comprehensive comfortable feeling including not only the thermal comfort but also the effects of that space. Kurazumi et al. [25] [26] quantified the human body effects using the outdoor thermal environment evaluation index ETFe [27] based on the heat balance of the human body. Even actual measurements in outdoor environments limited to thermal sensation showed that people prefer a lower temperature in summer than in winter, and tolerate higher temperatures in summer than in winter.

Previous research assumed a homogeneous and homogeneous steady state in 
a thermal environment in laboratory experiments. However, the usual environment is a non-uniform thermal environment that is uneven and unbalanced. Especially in outdoor environments, physical thermal environment factors fluctuate enormously and are in an unsteady state, so it is unusual that human body effects are quantified by using the comprehensive thermal environment evaluation index based on the heat balance of the outdoor environment as the evaluation axis.

As mentioned above, physiological functions of the human body are affected by annual temperature differences and the nutrition intake ratio, which climate change also affects. Effects of climate acclimatization due to seasonal variation may appear as seasonal differences in thermal sensation. It is suggested that thermal sensations change due to effects such as acclimatization to the thermal environment, but it is not limited to thermal sense according to specific sensation dependent heat exchange. In this study, we aimed to compare seasonal differences in thermal sensations by using the ETFe to quantify effects on thermal sensations of the human body in a tropical region climate with small annual temperature differences.

In this study, we measure the effects on thermal sensations of the human body in an outdoor thermal environment in winter in Bangkok, Thailand, a tropical region. Then, by comparing this with the results of the study of the dry season in Thailand by Kurazumi et al. [28], we clarify seasonal differences in effects on the human body. Given that the average temperature of the earth is forecast to rise, studying the effects on the human body from outdoor thermal environments in tropical regions may be important for considering how to spend time outdoors in the future.

\section{Experiment Plan}

In order to maintain consistency with the actual measurements in the outdoor environment that Kurazumi et al. [28] performed in the dry season in Bangkok, Thailand, the measurement items were the same as the dry season measurement.

\subsection{ETFe}

The sensational and physiological climatic environment index ETFe [25] [26] [27] [29] [30] converts the effects of the following parameters into a temperature-equivalent value: change in posture, air velocity, long-wave radiation in outdoor space, short-wave solar radiation, contact material surface temperature, and humidity.

The influence of the five environmental factors in relation to the heat balance of the human body can be expressed by the newly defined thermal environment evaluation indices of (i) heat transfer area combined with the thermal velocity field ( $T V F_{\text {hta }}$ ), which concerns air velocity, (ii) radiant heat transfer area combined with the effective radiation field concerning long-wave radiation in outdoor spaces $\left(E R F_{h t a L}\right)$, (iii) radiant heat transfer area combined with the effective radiation field concerning short-wave solar radiation in outdoor spaces $\left(E R F_{h t a s}\right)$, 
(iv) heat transfer area combined with the effective conduction field $\left(E C F_{h t a}\right)$, which concerns the surface temperature of the part that is contacted, and (v) the effective humidity field at the enhanced conduction-corrected modified effective temperature $\left(E H F_{E T F e}\right)$, which concerns humidity. Therefore, the addition of each temperature-converted factor is possible and the composite effect of the sensational and physiological temperature in outdoor spaces, as well as the discrete effect of each meteorological element, is quantified.

$$
\begin{aligned}
& E T F e=T_{a}+\frac{T V F_{h t a}}{h_{f L}}+\frac{E R F_{h t a}}{h_{f L}}+\frac{E C F_{h t a L}}{h_{f L}}+\frac{E H F_{\text {ETFe }}}{h_{f L}}+\frac{E R F_{\text {htaS }}}{h_{f L}} \\
& T V F_{\text {hta }}=\left(h_{o} f c l \text { Fclo } f_{\text {conv }}-h_{c} f c l F c l f_{\text {conv }}\right)\left(t_{s}-t_{a}\right) \\
& E R F_{h t a L}=h_{r L} f c l F c l f_{r a d}\left(t_{r L}-t_{a}\right) \\
& E C F_{h t a}=h_{d} \text { Fcld } f_{\text {cond }}\left(t_{f}-t_{a}\right) \\
& E H F_{E T F e}=L w h_{c} \text { fcl Fpcl }\left(p_{a}-0.5 p_{E T F e}^{*}\right) \\
& E R F_{h t a s}=R_{S} \\
& h_{f L}=h_{o} f c l F c l o f_{\text {conv }}+h_{r L} f c l F c l f_{r a d}+h_{d} \text { Fcld } f_{\text {cond }}
\end{aligned}
$$

where

ETFe: enhanced conduction-corrected modified effective temperature [K];

$T_{a}$ : air temperature $[\mathrm{K}]$;

$T V F_{h t a}:$ convective heat transfer area the combined with thermal velocity field $\left[\mathrm{W} / \mathrm{m}^{2}\right]$;

$E R F_{\text {htal }}$ : radiant heat transfer area combined with the effective radiation field concerning the long-wave radiation in outdoor space $\left[\mathrm{W} / \mathrm{m}^{2}\right]$;

$E R F_{h t a s}:$ radiant heat transfer area combined with the effective radiation field concerning the short-wave solar radiation in outdoor space $\left[\mathrm{W} / \mathrm{m}^{2}\right]$;

$E C F_{h t a:}$ heat transfer area combined with effective conduction field $\left[\mathrm{W} / \mathrm{m}^{2}\right]$;

$E H F_{E T F E}:$ effective humidity field at enhanced conduction-corrected modified effective temperature $\left[\mathrm{W} / \mathrm{m}^{2}\right]$;

$h_{r L}$ : radiant heat transfer coefficient concerning the long-wave radiation in outdoor space $\left[\mathrm{W} / \mathrm{m}^{2} \mathrm{~K}\right]$;

fcl: effective surface area of clothing [-];

$f_{\text {conv }}$ : convective heat transfer area factor [-];

$f_{\text {cond }}$. conductive heat transfer area factor $[-]$;

$f_{\text {rad. }}$. radiant heat transfer area factor [-];

Fcl: thermal efficiency factor of clothing in the exposed airflow area [-];

Fcld: thermal efficiency factor of clothing in the heat conduction area [-];

Fclo: thermal efficiency factor of clothing under the standard condition [-];

Fpcl: permeation efficiency factor of clothing [-];

$h_{c}$ : convective heat transfer coefficient $\left[\mathrm{W} / \mathrm{m}^{2} \mathrm{~K}\right]$;

$h_{d}$. resultant heat conductance $\left[\mathrm{W} / \mathrm{m}^{2} \mathrm{~K}\right]$;

$h_{f t}$ : sensible heat transfer coefficient in outdoor space $\left[\mathrm{W} / \mathrm{m}^{2} \mathrm{~K}\right]$;

$h_{o}$ : convective heat transfer coefficient under the standard condition $\left[\mathrm{W} / \mathrm{m}^{2} \mathrm{~K}\right]$; 


\section{$L$ : Lewis relation coefficient $[\mathrm{K} / \mathrm{kPa}]$;}

$p_{a}$ : water vapor pressure at the outdoor air temperature $[\mathrm{kPa}]$;

$p_{E T F e}^{*}$ : saturated water vapor pressure at enhanced conduction-corrected modified effective temperature $[\mathrm{kPa}]$;

$R_{S}$ : short-wave solar radiation heat gain of human body $\left[\mathrm{W} / \mathrm{m}^{2}\right]$;

$T_{s}$ : convection-corrected mean skin temperature $[\mathrm{K}]$;

$T_{f}$ surface temperature of the contacted material [K];

$T_{r L}$ : mean radiant temperature concerning long-wave radiation in outdoor space $[\mathrm{K}]$;

w. skin wettedness [-].

\subsection{Measurement Procedure}

The measurements were carried out in December in the Thai winter season. Mobile measurements were carried out on the campus of Chulalongkorn University, Bangkok, Thailand. A speed of movement slower than a normal walking speed of around $0.7 \mathrm{~m} / \mathrm{s}$ was used to transport the instruments for measuring the thermal environment. The observation points were drawn at random and the routes to the points were not decided in advance. With consideration for the burden on subjects, their physical strength, and mental fatigue, the experiments were concluded two hours after commencement of the mobile observations.

In indoor spaces such as a laboratory, it is exceedingly rare to test subjects in extremely hot or cold thermal environments. In general, in experiments that include a transition period or an uneven thermal environment, the time period of the exposure experiment is the subject of the investigation, so that the heat balance between the human body and the environment becomes almost a steady state. However, the thermal environment of outdoor spaces in summer can be harsh to the extent that there are cases of deaths due to heatstroke, whilst that of winter outdoor spaces can be harsh to the extent that the body temperature drops to the zone of hypothermia. Accordingly, one must avoid extended periods in outdoor spaces where one would be struck by direct solar radiation in a high-temperature environment. It is unavoidable for experiments on subjects in outdoor spaces to include a short transition period. Thus, taking into consideration the subjects' maintenance of a standing posture and the response time of the Assmann ventilated psychrometer, the actual measurements of the human body response and thermal environment in the mobile observations were performed after having set up the observation device and left it for ten minutes. Naturally, it can be conjectured that the longer the exposure time of the subjects, the more the response of the human body will differ, and the experimental period was determined with consideration for the safety of the subjects. Unlike in an indoor space, it is difficult to consider spending extended periods in an outdoor thermal environment that can be considered uncomfortable due to behavioral thermoregulation by means of refuge behavior from environmental stress.

As mentioned in the Introduction, adaptation to the thermal environment according to the influence of thermal environment history is apparent [18] 
[31]-[36], but a research method that removes the influence of environment history to the greatest possible extent was used in this research, similarly to $\mathrm{Ku}$ razumi et al. [25] [26] [28]. Subjects moved on foot to the observation point after sitting and being at rest at the control observation point 0 . While they were seated and at rest, the subjects were informed that psychological reporting involves thermally specific senses, that they would be asked to report the average sensation during the period of exposure, and that intake and excretion of liquids were prohibited until the conclusion of the experiment. The speed of movement of the subjects was slower than a normal walking speed of around $0.7 \mathrm{~m} / \mathrm{s}$, as detailed above, because of the movement of the trolley in which the research staff transported the measurement instruments.

After arriving at each measurement point, the subjects waited in a standing posture for five minutes while the test staff set up the measurement instruments for the thermal environment, and preparations for measurement were concluded. Thereafter, the subjects were exposed to the thermal environment in a standing posture for ten minutes, as stated above. The subjects were positioned around the thermal environment measurement instruments in a location where they did not obstruct the sunlight and they surrounded the thermal environment measurement instruments. As the subject of the research was the environment surrounding the observation stations, the point of gaze of the subjects was free and unfixed. After ten minutes' exposure, the subjects reported the average thermal sensation and the average thermal comfort of the whole body that they experienced while exposed at the observation point $(21 \mathrm{~cm} * 28.5 \mathrm{~cm})$.

\subsection{Outline of the Observation Points}

A summary of the observation points is shown in Table 1. For the measurements, observation points were selected taking into consideration the condition of the ground surface, such as bare ground where the surface is gravel or soil, paved ground such as concrete, asphalt, or blocks, green areas covered with plants, and water surfaces comprising the solid angle of the total celestial sphere

Table 1. Summary of observation points.

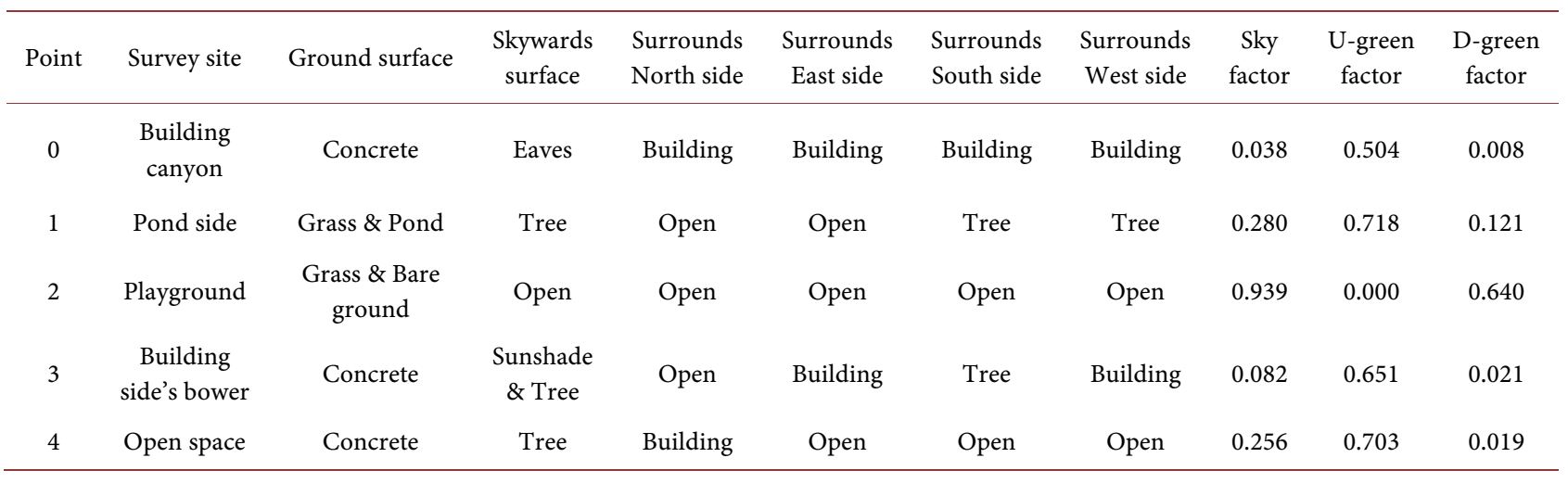

Sky factor is defined as the ratio of configuration factor of sky to semi celestial sphere. U-green factor is defined as the ratio of upward green, water surface and the like solid angles to semi celestial sphere solid angle. D-green factor is defined as the ratio of downward green, water surface and the like solid angles to semi celestial sphere solid angle. 
(hereafter, green cover ratio), while taking into consideration the condition of the sky factor due to buildings, trees, and so on. Five observation points were chosen.

\subsection{Subjects}

The subjects comprised 15 healthy young Thais, with four young male and 11 young female university students. The height of the 11 females was $158.0 \pm 5.9$ $\mathrm{cm}$ and their weight was $47.8 \pm 7.9 \mathrm{~kg}$. The height of the four male university students was $174.6 \pm 4.6 \mathrm{~cm}$ and their weight was $70.9 \pm 11.3 \mathrm{~kg}$. Thus, they were considered to be subjects of average physical stature.

In accordance with the Declaration of Helsinki [37], the details of the experiment were explained sufficiently well in advance to the subjects and their consent was obtained for their voluntary participation.

\subsection{Measured Parameters}

Air temperature, humidity, air velocity, short-wave solar radiation heat quantity, long-wave radiation heat quantity, ground surface temperature, and water surface temperature were measured. The air temperature and humidity were measured at a height of $0.9 \mathrm{~m}$ above the ground by means of an Assmann ventilated psychrometer. The average air velocity was measured for five minutes at a height of $0.9 \mathrm{~m}$ above the ground using an omnidirectional anemometer (Kanomax Japan: 6533; measurement range: $0.05-5.00 \mathrm{~m} / \mathrm{s}$ ). With regard to the short-wave thermal radiation heat quantity in the visible to near- and mid-infrared regions and the terrestrial thermal radiation in the far infrared region, thermal radiation heat quantities in the downwards and upwards directions were measured at a height of $0.9 \mathrm{~m}$ above the ground using a long-wave and short-wave radiometer (Climatec: CHF-NR01; sensitivity: $10 \mathrm{mV} / \mathrm{Wm}^{-2}$; short-wave range: 285 - 3000 $\mathrm{nm}$; long-wave range: 4500 - $40000 \mathrm{~nm}$ ). The ground surface temperature in the vicinity of the human body was measured by means of a radiation thermometer (Nippon Avionics: F30S; measurement wavelength: $8-14 \mu \mathrm{m}$; measurement range: $-20^{\circ} \mathrm{C}-100^{\circ} \mathrm{C}$; sensitivity: $0.1^{\circ} \mathrm{C}$ ). The sky factor was measured by means of a photograph of the sky taken $0.9 \mathrm{~m}$ above the ground at the observation point using a fisheye lens with an orthographic projection format (Yasuhara: Madoka $1807.3 \mathrm{~mm} \mathrm{f} / 4$ ) and a $35 \mathrm{~mm}$ digital SLR camera (Sony: $\alpha 7$ ). The ratio of green and water surface solid angles to the celestial globe solid angle was calculated by using a converted photograph of equisolid angle projection format from a photograph in orthographic projection format. The albedo, sky temperature, and ground surface temperature were calculated from each directional component of the short-wave thermal radiation heat quantity and the long-wave thermal radiation heat quantity. Moreover, it is indispensable for the surround-

ing ground surface temperature to calculate the heat conduction. The ground surface temperature in the vicinity of the human body was measured with a radiation thermometer. For calculating the long-wave thermal radiation heat quantity, the sky and ground surface temperatures were used. 
The skin temperature was measured at the positions of the head, trunk, arm, hand, thigh, lower leg, and foot. The skin temperature was measured as the physiological condition of the human body by means of a thermistor thermometer (Nikkiso-Thermo, N542R and ITP8391; measurement range: $-50^{\circ} \mathrm{C}$ to $230^{\circ} \mathrm{C}$; resolution: $0.01^{\circ} \mathrm{C}$ ). The calculation of the mean skin temperature used for the physiological response of the human body was performed using a weighting coefficient that takes into account heat conduction [38]. The value calculated by means of the thermoregulation model of Kurazumi et al. [39] was also used for the physiological quantity that became a missing value. The subjects freely selected their clothing to be suitable for the weather on the measurement day. The quantity of clothing of the subjects was evaluated by the "clo" value by composite ensemble method for layering the clothing reported by the subjects [40] [41]. With regard to the psychological condition of the human body, the psychological response was measured after staying at the observation point for ten minutes by means of rating the whole-body thermal sensation (seven grades), and wholebody thermal comfort (five grades).

These explanatory variables of thermal sensation are direct environmental stimuli to thermal sensation, and greatly affect physiological and psychological reactions of the human body: temperature, humidity, wind speed, short-wavelength solar radiation heat, long-wavelength radiant heat, surface temperatures of materials that contact the human body, etc. In this study, given that the psychological reaction of the human body in an outdoor environment is likely to cause many disturbances and variations, as a criterion for comparing explanatory variables for deriving results of regression analysis with greater usefulness from a practical point of view, the significance probability was set to $10 \%$. JMP 12.2.0 (SAS Institute Japan) was used for statistical analysis.

\section{Result}

\subsection{Observed Weather Summary}

Table 2 shows measurement data of observation points on measurement dates. The temperature dropped below $30^{\circ} \mathrm{C}$ at some observation points. The climate of Bangkok was in winter, during which temperatures were relatively low. There was a large amount of downward short-wave solar radiation at open observation points with a high sky percentage, but there was much less downward shortwavelength solar radiation at observation points where sunlight was obstructed by trees etc. with a low sky ratio. The effect of sunlight is very noticeable.

There were great amounts of long-wavelength radiation at all the observation points. Even if one is sheltered in a place with solar radiation shielding avoiding short-wavelength solar radiation, one still receives a lot of heat radiation. At observation points with a concrete pavement where there is high heat capacity and strong effects of short-wavelength solar radiation, the ground surface temperature in the vicinity of the observation point is remarkably higher than at other observation points. Observation points 2 and 4, which easily receive short-wavelength solar radiation, have higher surface temperatures than other observation 
Table 2. Results of field survey.

\begin{tabular}{|c|c|c|c|c|c|c|c|c|c|c|}
\hline Date & Time & Point & $\mathrm{Ta}\left[{ }^{\circ} \mathrm{C}\right]$ & $\operatorname{Tf}\left[{ }^{\circ} \mathrm{C}\right]$ & RH [\%] & $\mathrm{Va}[\mathrm{m} / \mathrm{s}]$ & RSdwn $\left[\mathrm{W} / \mathrm{m}^{2}\right]$ & RSup $\left[\mathrm{W} / \mathrm{m}^{2}\right]$ & RLdwn $\left[\mathrm{W} / \mathrm{m}^{2}\right]$ & $\operatorname{RLup}\left[\mathrm{W} / \mathrm{m}^{2}\right]$ \\
\hline 23 Dec. & $11: 11$ & 0 & 27.9 & 28.9 & 69.2 & 0.18 & 26.14 & 4.22 & 470.13 & 466.57 \\
\hline 23 Dec. & $11: 34$ & 1 & 28.6 & 27.1 & 65.8 & 1.52 & 53.40 & 12.75 & 467.13 & 462.94 \\
\hline 23 Dec. & $11: 54$ & 2 & 29.5 & 34.2 & 62.2 & 1.38 & 476.64 & 64.94 & 441.98 & 496.27 \\
\hline 23 Dec. & $12: 12$ & 3 & 29.4 & 30.1 & 61.6 & 0.75 & 27.88 & 0.96 & 477.83 & 477.52 \\
\hline 23 Dec. & $12: 30$ & 4 & 29.5 & 35.1 & 63.4 & 0.84 & 168.79 & 41.69 & 473.46 & 497.06 \\
\hline 23 Dec. & $12: 41$ & 0 & 28.5 & 30.9 & 65.2 & 0.18 & 9.03 & 0.00 & 476.41 & 473.89 \\
\hline 23 Dec. & $14: 17$ & 0 & 28.5 & 29.7 & 66.4 & 0.20 & 8.86 & 3.53 & 471.94 & 468.36 \\
\hline 23 Dec. & $14: 39$ & 4 & 29.3 & 33.2 & 66.9 & 0.49 & 44.10 & 13.49 & 472.09 & 487.82 \\
\hline 23 Dec. & $14: 54$ & 3 & 29.5 & 30.1 & 64.6 & 0.45 & 11.79 & 1.38 & 475.88 & 475.91 \\
\hline 23 Dec. & $15: 12$ & 2 & 30.0 & 32.7 & 62.6 & 0.63 & 279.40 & 46.43 & 449.59 & 488.68 \\
\hline 23 Dec. & $15: 28$ & 1 & 29.5 & 28.6 & 63.4 & 0.63 & 33.22 & 4.64 & 476.80 & 469.72 \\
\hline 23 Dec. & $15: 35$ & 0 & 28.3 & 29.3 & 61.3 & 0.13 & 3.61 & 0.00 & 476.32 & 474.10 \\
\hline 24 Dec. & $10: 36$ & 0 & 28.8 & 28.7 & 67.2 & 0.16 & 25.15 & 4.38 & 478.71 & 471.29 \\
\hline 24 Dec. & $10: 58$ & 4 & 32.0 & 38.3 & 54.6 & 0.65 & 674.77 & 151.12 & 485.96 & 515.77 \\
\hline 24 Dec. & 11:14 & 3 & 30.2 & 30.9 & 59.8 & 0.29 & 16.05 & 0.00 & 486.17 & 481.98 \\
\hline 24 Dec. & $11: 30$ & 2 & 31.5 & 33.3 & 58.5 & 1.12 & 249.16 & 44.08 & 445.10 & 495.25 \\
\hline 24 Dec. & $11: 45$ & 1 & 31.0 & 28.9 & 58.2 & 0.53 & 68.33 & 18.41 & 848.88 & 477.87 \\
\hline 24 Dec. & $11: 52$ & 0 & 30.0 & 30.5 & 60.2 & 0.16 & 22.68 & 1.17 & 489.03 & 477.77 \\
\hline 24 Dec. & $13: 42$ & 0 & 30.4 & 30.8 & 61.7 & 0.16 & 13.94 & 6.41 & 481.45 & 473.34 \\
\hline 24 Dec. & $13: 59$ & 1 & 30.8 & 29.1 & 59.1 & 0.65 & 27.36 & 5.92 & 477.32 & 471.70 \\
\hline 24 Dec. & $14: 12$ & 2 & 30.8 & 32.3 & 63.7 & 0.29 & 271.48 & 43.00 & 456.38 & 493.25 \\
\hline 24 Dec. & $14: 27$ & 3 & 31.4 & 31.2 & 56.8 & 1.12 & 59.01 & 5.93 & 491.48 & 486.10 \\
\hline 24 Dec. & $14: 27$ & 3 & 31.4 & 31.2 & 56.8 & 1.12 & 59.01 & 5.93 & 491.48 & 486.10 \\
\hline 24 Dec. & $14: 51$ & 0 & 30.9 & 31.1 & 55.3 & 0.16 & 15.72 & 0.00 & 496.67 & 484.30 \\
\hline
\end{tabular}

$\mathrm{Ta}$ is the range of air temperature. Tf is the range of ground surface temperature in the vicinity of the human body. RH is relative humidty. Va is air velocity. RSdwn is downward short wave solar radiation. RSup is upward short wave solar radiation. RLdwn is downward long wave radiation. RLup is upward long wave radiation.

points. For example, there is very little contact area between the standing-posture human body and the ground surface, but it is conjectured that the heat acquisition of the human body by heat conduction strongly affects contact skin temperature. In addition, it is conjectured that the high surface temperature in the vicinity of the human body strongly affects the heat radiation amount because the shape factor increases. The trend of the measured results of short- wavelength solar radiation and long-wavelength radiation at the observation points was similar to the dry season results of Kurazumi et al. [28].

The measured average value of relative humidity is $60.4 \%$, the standard deviation is $7.4 \%$, and no notable difference in actual measurement results is shown. Therefore, there may be weak effects on the sensed temperature due to the dif- 
ference in the evaporative heat exchange amount.

The average wind speed was a relatively calm $2 \mathrm{~m} / \mathrm{s}$ or less through all the observations. The standard deviation was $0.4 \mathrm{~m} / \mathrm{s}$. Therefore, a difference in convective heat exchange amount may weakly affect sensed temperature. However, at the open observation points 1,2 and 4, which easily receive short-wavelength solar radiation, the average wind speed is higher than at observation points 0 and 3, which are in a canyon space surrounded by buildings. This may affect thermal sensation as a factor of environmental change.

Oliveira and Andrade [42] state that wind speed has the strongest effect on overall comfort. Kurazumi et al. [29] [30] state that the effects of air current in summer and winter are one of the factors that cause the outdoor thermal environment to affect the thermal sensation and comfort of the human body. It is possible for the human body to experience discomfort due to variation in environmental factors, and this experience can be considered to induce relative comfort. Accordingly, variations with an effect that mitigates thermal action are considered to be variables for discomfort with regard to other environmental factors as well.

\subsection{Relationship between Thermal Sensation and Observation Point}

Define Figure 1 shows the relation between thermal sensation and exposure points. The "slightly warm" to "hot" for observation point 2 with a high sky factor expressed as a percentage is $96.9 \%$, which is remarkably high. The observation point 2 ground surface is covered with plants. At these observation points, in spaces with nothing to block the direct sunlight, feelings of hot sensation are considered to be more apparent. On the other hand, the "neutral" to "cool" of observation points 0 and 3, which have a low sky factor, expressed as percentages are respectively $80.3 \%$ and $78.1 \%$, which are remarkably high.

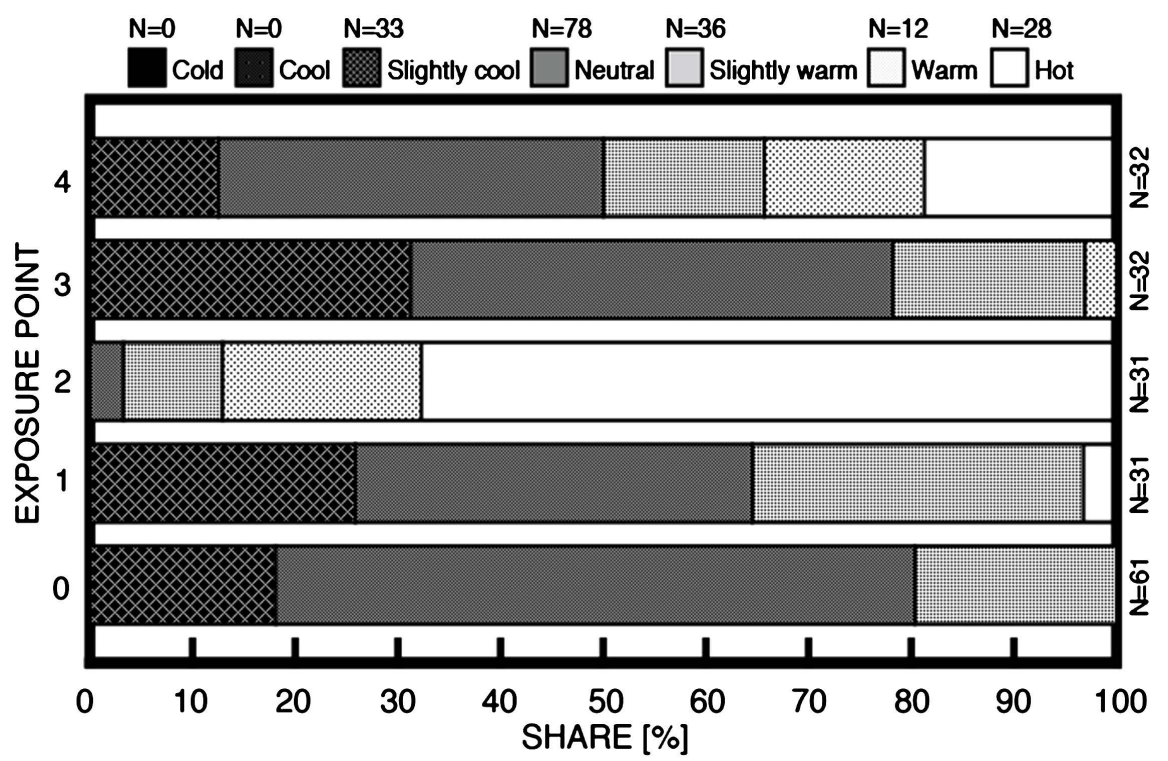

Figure 1. Relation between thermal sensation and exposure points. 
Observation points 1 and 4, which have a high upward green factor, expressed as a percentage that is intermediate response that is in the range from observation points 0 and 3 with a low sky factor to observation point 2 with a high sky factor. The "slightly warm" to "hot" for observation points 1 and 4, expressed as percentages, is respectively $35.5 \%$ and $50.0 \%$. At observation points 0 and 3 , which have a low sky factor, direct sunlight is almost blocked by buildings and trees. However, at observation points 1 and 4, sunlight filtering through the trees is considered to show an intermittent effect. The observation point 1 ground surface is almost covered with plants. Also, the observation point 4 ground surface is almost covered with concrete pavement. At observation point 4, which has the influence of the reflected sunlight, feelings of hot sensation are considered to be more apparent.

The result of testing the homogeneity of responses was $\mathrm{p}<0.01\left(\chi^{2}=127.79\right)$, thereby showing a significant difference. In particular, at observation point 0 it was $\mathrm{p}<0.01$ in contrast to observation points 2 and 4 , which showed a significant difference. Then, at observation point 1 it was again $\mathrm{p}<0.01$ in contrast to observation points 2 and 4, thereby showing a significant difference. The effect of blocked sunlight and ground cover is considered to show remarkable results in terms of thermal sensation. Therefore, similarly to the indications of Kurazumi et al. [28] [43], the long-wave thermal radiation from the surface temperature of the building and the ground surface is increased even in winter tropical urban climate.

\subsection{Relationship between Thermal Comfort and Observation Point}

Figure 2 shows the relation between thermal comfort and exposure points. The "comfortable" to "slightly uncomfortable" for observation point 2 with a high sky factor expressed as a percentage is $19.4 \%$, which is remarkably low. On the

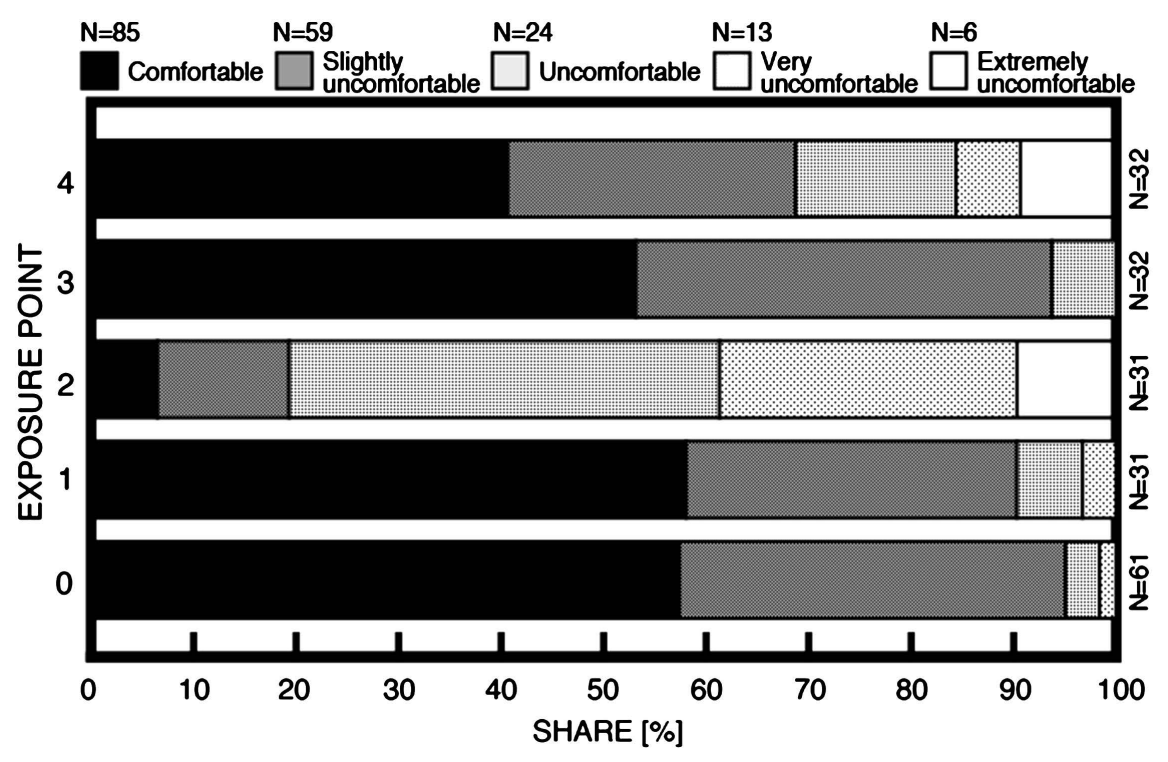

Figure 2. Relation between thermal comfort and exposure points. 
other hand, observation points 0 and 3 with a low sky factor and observation point 1 with a high green factor expressed as percentages are respectively $95.1 \%$, $93.7 \%$, and $90.4 \%$, which are remarkably high. This is considered to show the effects of blocking direct sunlight. In spaces with nothing to block the direct sunlight, feelings of discomfort are considered to be more apparent.

The sky factor for observation point 1 is almost equal to that for observation point 4 . However, the "uncomfortable" to "extremely uncomfortable" for observation point 4 expressed as a percentage is $31.3 \%$, which is remarkably high compared with observation point 1 . The downward green factor for observation point 4 is lower than that for observation point 1 . Therefore, at observation point 4 , which has the influence of the reflected sunlight, feelings of discomfort are considered to be more apparent. Moreover, this is considered to show the influence of visual stimuli such as natural elements including vegetation like greenery [28] [43] [44] [45].

The result of testing the homogeneity of responses was $\mathrm{p}<0.01\left(\chi^{2}=81.28\right)$, thereby showing a significant difference. In particular, at observation point 0 it was $\mathrm{p}<0.01$ in contrast to observation points 2 and 4 , thereby showing a significant difference. This is considered to show the effects of blocking direct sunlight and reflected sunlight. In spaces with nothing to block the direct sunlight and reflected sunlight, feelings of discomfort are considered to be more apparent. The effect of blocked sunlight and ground cover is considered to show remarkable results in terms of thermal comfort.

\section{Discussion}

The following discussion will clarify seasonal differences regarding effects on the human body, by comparison with the results of research in Thailand's dry season by Kurazumi et al. [28].

Experiments with subjects measuring physiological and psychological quantities as human body reactions are rarely performed using a large number of subjects. Therefore, although there are few subjects in this study, they are considered meaningful as new data.

\subsection{Relationship between Air Temperature and Mean Skin Temperature}

Figure 3 shows the relationship between the air temperature and mean skin temperature. The outdoor environmental conditions are concentrated in a narrow range, so it is difficult to obtain a constant tendency in the mean skin temperature distribution. Mean skin temperature of the winter season shows wider distribution than the dry season, showing remarkable individual differences.

When the air temperature is in the range of about $30^{\circ} \mathrm{C}$, detailed examination shows that mean skin temperature tends to increase as the air temperature increases. In a range where the air temperature is about $31^{\circ} \mathrm{C}$ or more, there is a tendency for mean skin temperature distribution to be low, unlike the tendency shown when the air temperature is in the range up to about $30^{\circ} \mathrm{C}$. It cannot be 


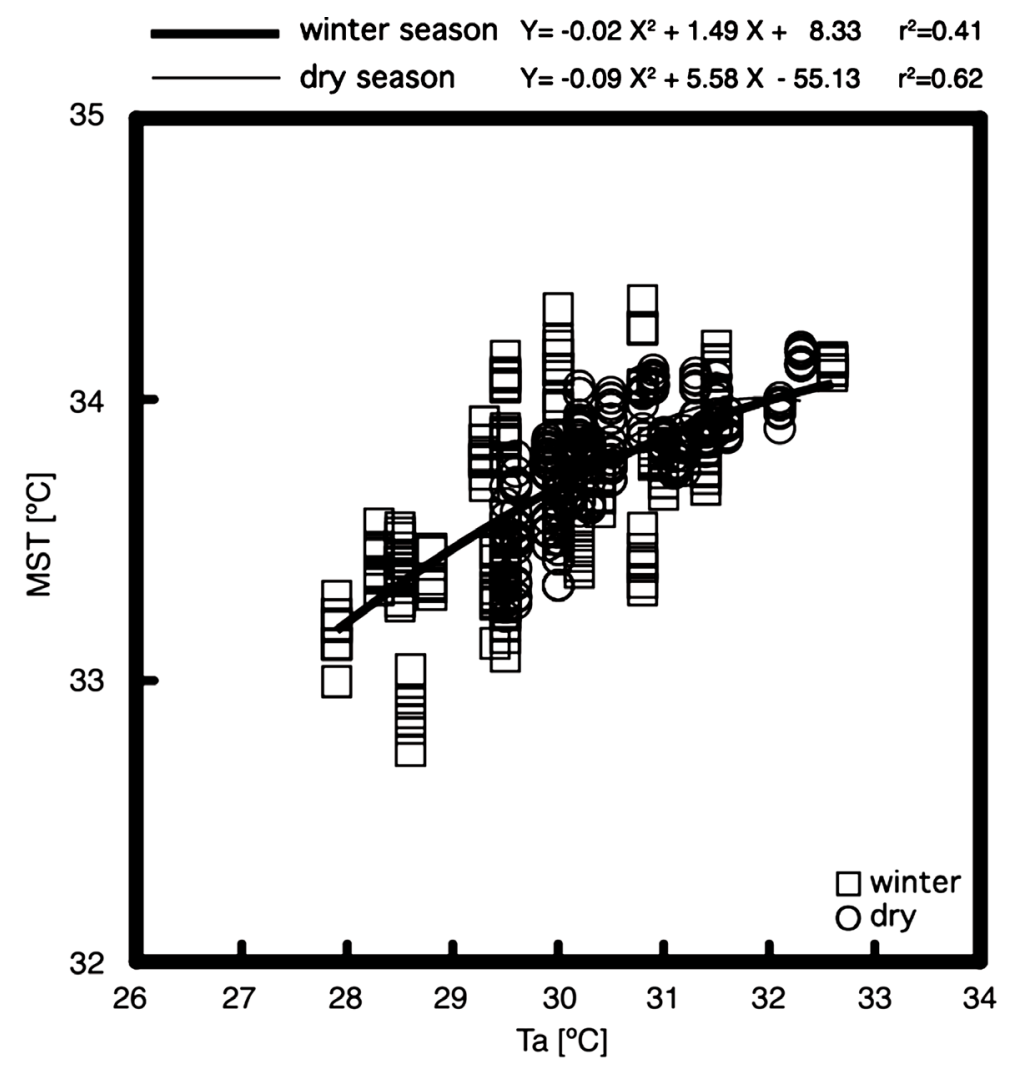

Figure 3. Relationship between Ta and MST. Ta is air temperature. MST is mean skin temperature.

clarified when the air temperature is in the range of about $31^{\circ} \mathrm{C}$ or more because there are few samples, but similar to the results shown in the outdoor experiment of Kurazumi et al. [26], it seems there is a cooling effect due to the rapid increase of water evaporation calories due to perspiration, which suppresses the rise in temperature of the skin surface.

Focusing on the regression line, we used a nonlinear quadratic regression model to test for equivalence between winter and the dry season. Between winter and the dry season the slope, intercept and secondary regression coefficient were $\mathrm{p}<0.10$, thereby showing a significant difference. Therefore, in the range of the results of the air temperature in this study, it seems that the effects of seasonal differences appeared in the amount of change to mean skin temperature.

As we have not studied the endocrinology and metabolism details, the effect of acclimatization to the thermal environment due to seasonal variation is unknown. However, even in Bangkok, Thailand, where there are small seasonal differences in the air temperature, this study inferred that effects of environmental history appear as seasonal differences.

Thus, the following discussion will clarify seasonal differences regarding effects on the thermal sense, by using of the outdoor thermal environment evaluation index ETFe [27]. The ETFe [27] is based on the heat balance of the human body. Accordingly, the calculation of the mean skin temperature used for the calculation of the heat balance of the human body was performed using a 
weighting coefficient that takes into account the convective heat transfer area [46]. In calculating the body surface area of the human body, we used the calculation formula of Kurazumi et al. [47]. The values of Kurazumi et al. [48] were used for the convective heat transfer area factor, the radiant heat transfer area factor, and the conduction heat transfer area factor for the human body. The value of Miyamoto et al. [49] was used for the projection area ratio of the human body. The values of Kuwabara et al. [50] were used for the radiant heat transfer coefficient and convective heat transfer coefficient of the human body. The value of Hendler et al. [51], found from the reflectance by the skin of electromagnetic waves with wavelengths of $3 \mu \mathrm{m}$ or more, was used for the emissivity of the human body. The values of Hendler et al. [51] and Elam et al. [52], found from the reflectance by skin of electromagnetic waves with wavelengths of $3 \mu \mathrm{m}$ or less, were used for the solar radiation absorption coefficient of the human body. The short-wave solar radiation heat gain of the human body is affected by the shortwave solar radiation absorption. According to VDI3787-2 [53], the direct solar radiation absorption of a clothed body is 0.7. However, Watanabe et al. [54] showed that the direct solar radiation absorption of a body clothed in black is 0.76 and that of a body clothed in white is 0.38 . Also, the direct solar radiation absorption of other clothing combinations or everyday clothing falls within the range of direct solar radiation absorption for a body in black or white clothing. In this study, a value for the short-wave solar radiation absorption of 0.7 , which is standard for a naked body, was used. It was difficult to measure the skin wetness. Therefore, the calculation method used to arrive at these values of skin wetness was the thermoregulation model of Kurazumi et al. [39]. In addition, the value calculated by means of the thermoregulation model of Kurazumi et al. [39] was also used for the physiological quantity that became a missing value. The standard air velocity was considered to be $0.1 \mathrm{~m} / \mathrm{s}$ and the standard clothing was considered to be a naked body ( 0 clo) in this research. The ETFe index theoretically proposed by Kurazumi et al. [27] [29] was calculated from weather observation values, the skin temperature of the human body, and the clothing value.

\subsection{Relationship between ETFe and Thermal Sensation}

Figure 4 shows the relationship between the ETFe and Thermal sensation. It shows a tendency for people to report on the "hot" side when the ETFe becomes higher. Thermal sensation shows a wide distribution from "cool" to "hot," showing remarkable individual differences. Kurazumi et al. [28] point out that variation in thermal sensation in outdoor spaces becomes large not only due to the psychological response to the thermal action, but also to the effects of other environmental stimuli in outdoor spaces. Psychological reactions of the human body may be changed by the effects of other environmental stimuli in environments with moderate thermal environment stimulation to the human body. However, in environments with remarkably strong thermal environment stimulation, psychological reactions of the human body could be focused on responses to thermal environment stimulation. 


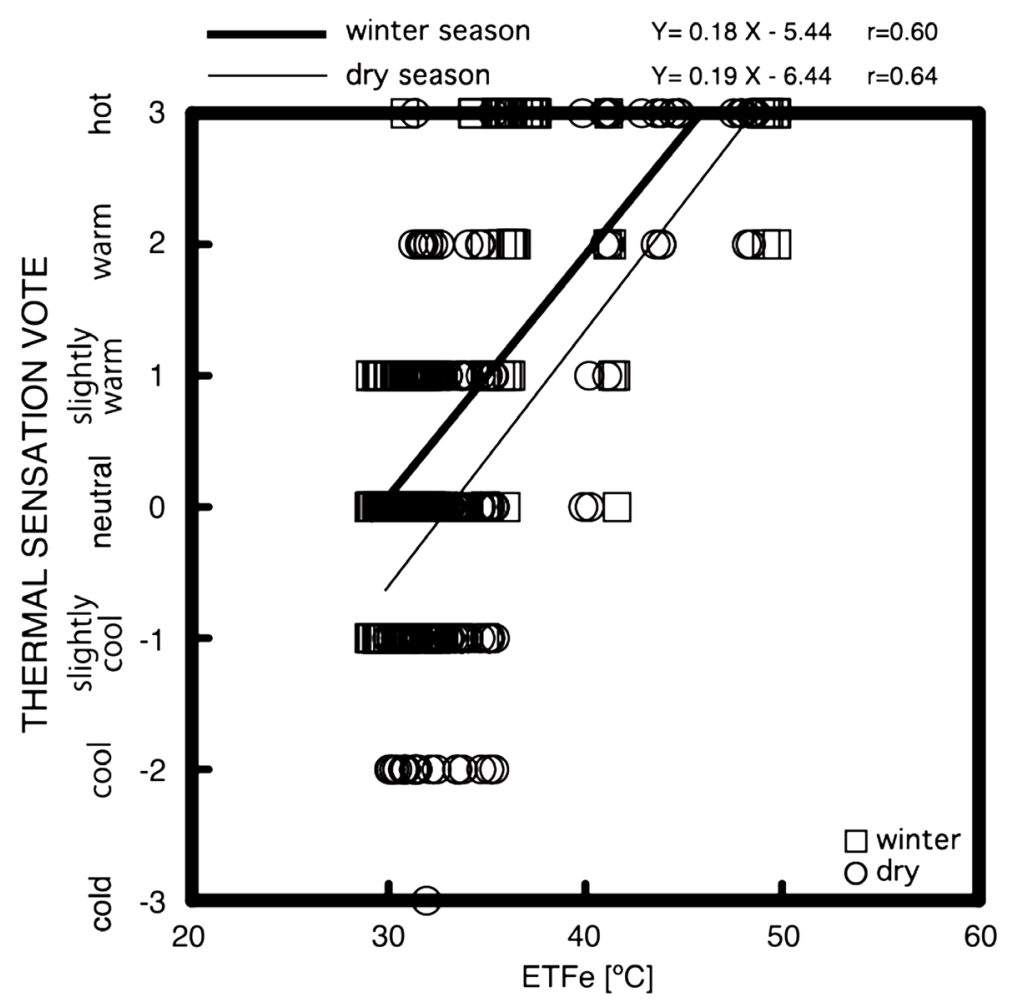

Figure 4. Relation between ETFe and thermal sensation.

When the ETFe is in the range $30^{\circ} \mathrm{C}-40^{\circ} \mathrm{C}$, thermal sensation in the range from "slightly cool" to "slightly warm" tends to be reported. Similarly to what Kurazumi et al. [25] [26] [29] point out, it seems that expectation of comfort in the outdoor space is originally low, judging that it is not a comfortable thermal environment, so the ETFe was acceptable even under high thermal environmental conditions. Although it is uncomfortable thermally, it could be that people tolerate a wider range of thermal environments in outdoor spaces where they can change the selection of place and viewpoint at their own will. In other words, it is thought that due to the degree of freedom of behavior in the experimental environment, large fluctuations in the psychological reactions of the human body occurred in the outdoor space [26]. The outdoor thermal environmental factors of short-wavelength solar radiation, long-wavelength radiation and air current are uneven and non-targeted evaluation factors. These evaluation factors may contribute to local effects on the human body, even if the heat balance in the whole body is the same.

Focusing on the regression line, when people report in the range from "slightly cool" to "slightly warm", which are considered to be moderate thermal environments, the $E T F e$ is $24.1^{\circ} \mathrm{C}$ to $35.0^{\circ} \mathrm{C}$ in winter, and $28.0^{\circ} \mathrm{C}$ to $38.3^{\circ} \mathrm{C}$ in the dry season. When people report a neutral thermal sensation that is neither hot nor cold, the ETFe is $29.6^{\circ} \mathrm{C}$ in the winter season and $33.1^{\circ} \mathrm{C}$ in the dry season. There is no large difference in the slope of the regression line, and it seems there is a tendency in winter for people to prefer a thermal environment that is about $3.5^{\circ} \mathrm{C}$ lower than in the dry season. People like winter temperatures that 
are lower than they like in summer, and tolerate higher temperatures in summer than in winter, as discovered by Höppe [17], Nikolopoulou and Steemers [18], Spagnolo and de Dear [19], Nakano and Tanabe [20], Ahmed [21], Oliveira and Andrade [22], Lin and Matzarakis [23], Cheng et al. [24], and Kurazumi et al. [25] [26]. The climate of Bangkok in Thailand is hottest in the dry season, so it can be regarded as summer. Therefore, this study also inferred that effects of environmental history appear as seasonal differences.

The result of testing the parallelism of the regression line was $\mathrm{p}>0.10$ (RMSE $=1.01, F=0.22, \mathrm{p}=0.64)$, and no significant difference in the parallelism of the regression line was shown. The result of testing the homogeneity of the regression was $\mathrm{p}<0.10$ (Welch's t-test, RMSE $=1.29, t=3.80, \mathrm{p}<0.01$ ), indicating a significant difference in the homogeneity of the regression line. Therefore, in the range of the results of the ETFe in this study, it seems that the effects of seasonal differences, which seem to be lower in winter than in the dry season, appeared in the amount of change to thermal sensation.

\subsection{Relationship between ETFe and Thermal Comfort}

Figure 5 shows the relationship between the ETFe and thermal comfort. As the ETFe increases, the strength of "uncomfortable" tends to increase. The feeling of comfort shows a wide distribution from "comfortable" to "extremely uncomfortable," thereby showing remarkable individual differences. Very few subjects reported "extremely uncomfortable," but in winter they reported "extremely uncomfortable" at a lower ETFe than in the dry season. As described in the relationship between the ETFe and thermal sensation, it is thought that the variation

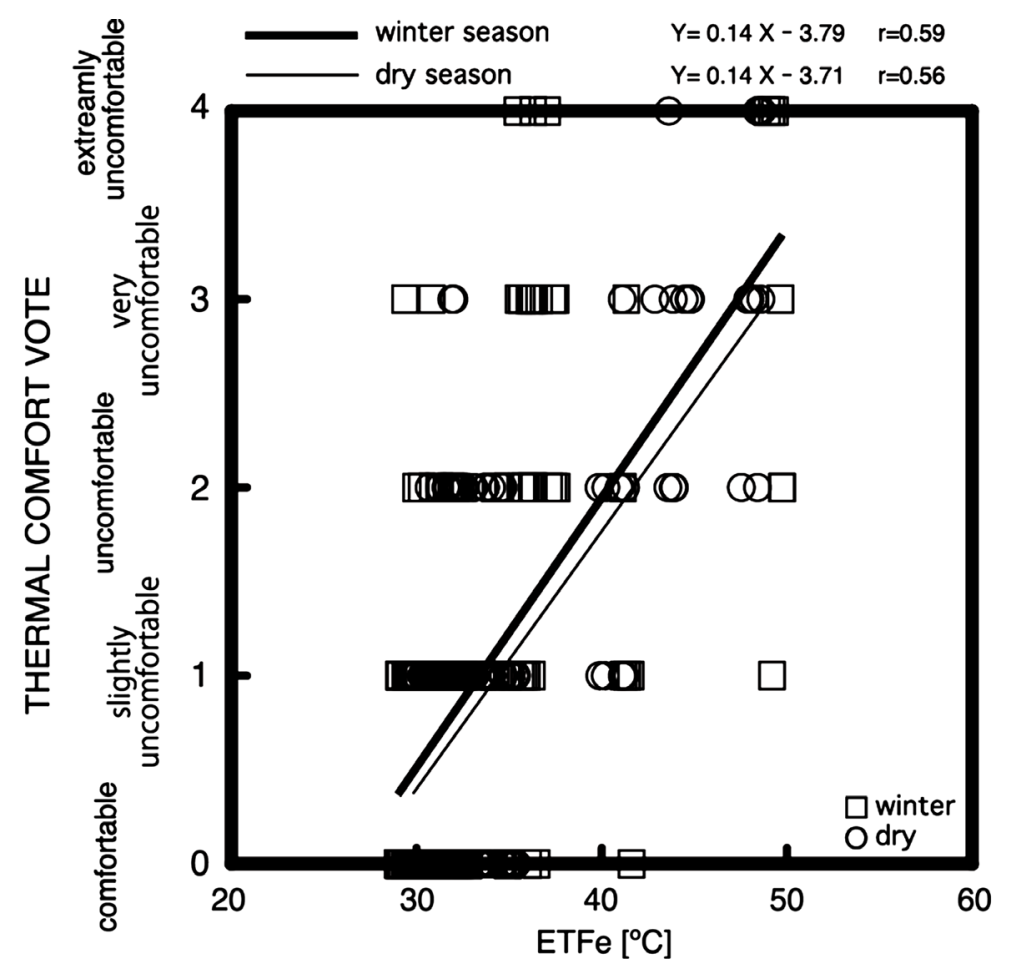

Figure 5. Relation between ETFe and thermal comfort. 
in psychological reactions of the human body is increased not only by psychological responses to thermal actions, but also by other environmental stimuli in the outdoor space.

For determining comfort, not only are physical and physiological environmental factors important but also psychological environmental stimulation, as shown by Humphreys [32], Brager and de Dear [55], de Dear and Brager [33], Nikolopoulou et al. [34], Nikolopoulou and Steemers [18], Knez and Thorsson [35], Nikolopoulou and Lykoudis [31], Kántor and Unger [36], and Kurazumi et al. [56]. They state that adaptation to a thermal environment will occur due to the effects of cultural background, and the history of thermal environments, such as experience of staying in thermal environments such as hot and cold environments, anticipation of a thermal environment, behavioral thermoregulation, and exposure time.

In this research, we use an experimental method that isolates environmental history as much as possible, but it seems that there are effects of thermal environment history, and an expectation of an environmental sheltering thermal environment accompanying mobile observation. Kurazumi et al. [25] state that $38.5^{\circ} \mathrm{C}$ is the upper-limit $E T F e$ for the optimal environmental range in summer. After the ETFe exceeds that upper-limit temperature, the variation becomes large. Therefore, we instruct subjects to report thermal comfort according to specific sensation depending on heat exchange, but we cannot deny the possibility that they are reporting comprehensive thermal comfort including the effects of spatial impression, etc. As pointed out by Kurazumi et al. [26], outdoor thermal environmental factors (short-wavelength solar radiation, long-wavelength radiation, and airflow) are uneven and non-targeted evaluation factors, and the effects of parameters of these environmental factors could cause variations in human body reactions. It is possible for the human body to experience discomfort due to variation in environmental factors, and this experience can be considered to induce relative comfort. Accordingly, variations with an effect that mitigates thermal action are considered to be variables for discomfort with regard to other environmental factors as well.

Focusing on the regression line, when people report "comfortable", the ETFe is $26.4^{\circ} \mathrm{C}$ in winter and $27.1^{\circ} \mathrm{C}$ in the dry season. The ETFe when people report "uncomfortable" is $40.4^{\circ} \mathrm{C}$ in winter and $41.7^{\circ} \mathrm{C}$ in the dry season. Similarly to what Kurazumi et al. [25] [26] [29] point out, it seems that the expectation of comfort in outdoor spaces is originally low, and people judge that it is not a comfortable thermal environment, so the ETFe is tolerable even under high thermal environmental conditions. The slope of the regression line is slightly greater in winter than in the dry season, so it seems that reactions to thermal sensation for thermal comfort appear more strongly in winter than in the dry season, even at almost the same ETFe.

The result of testing the parallelism of the regression line was $\mathrm{p}>0.10$ (RMSE $=0.77, F=0.13, \mathrm{p}=0.72$ ), and no significant difference was shown in the parallelism of the regression line. The result of testing the homogeneity of the regres- 
sion was $\mathrm{p}>0.10$ (Welch's t-test, RMSE $=0.97, t=0.03, \mathrm{p}=0.98$ ), thereby showing no significant difference in the homogeneity of the regression line. Therefore, it seems that within the range of ETFe results of this experiment, the effects of seasonal differences do not exert a large influence on the amount of change to thermal comfort.

The laboratory experiment of Fanger [4] found no seasonal differences in thermal comfort. However, according to a questionnaire survey at the office of Miura [57], the thermal neutral temperature has a seasonal difference, which is higher in summer than in winter. In experiments with subjects in outdoor environments by Kurazumi et al. [25] [26], in Japan, where the annual difference in temperature is larger than in Bangkok, people tolerate higher temperatures in summer than in winter, and they state that thermal comfort has seasonal differences. In 2016, the annual difference in temperature in Bangkok was around $4^{\circ} \mathrm{C}$, but the annual difference in temperature in Tokyo was around $21^{\circ} \mathrm{C}$ [58].

\subsection{Relationship between Thermal Sensation and Thermal Comfort}

Figure 6 shows the relationship between thermal sensation and thermal comfort. Thermal comfort's "uncomfortable" strength tends to increase as the thermal sensation stage increases. This shows remarkable individual differences.

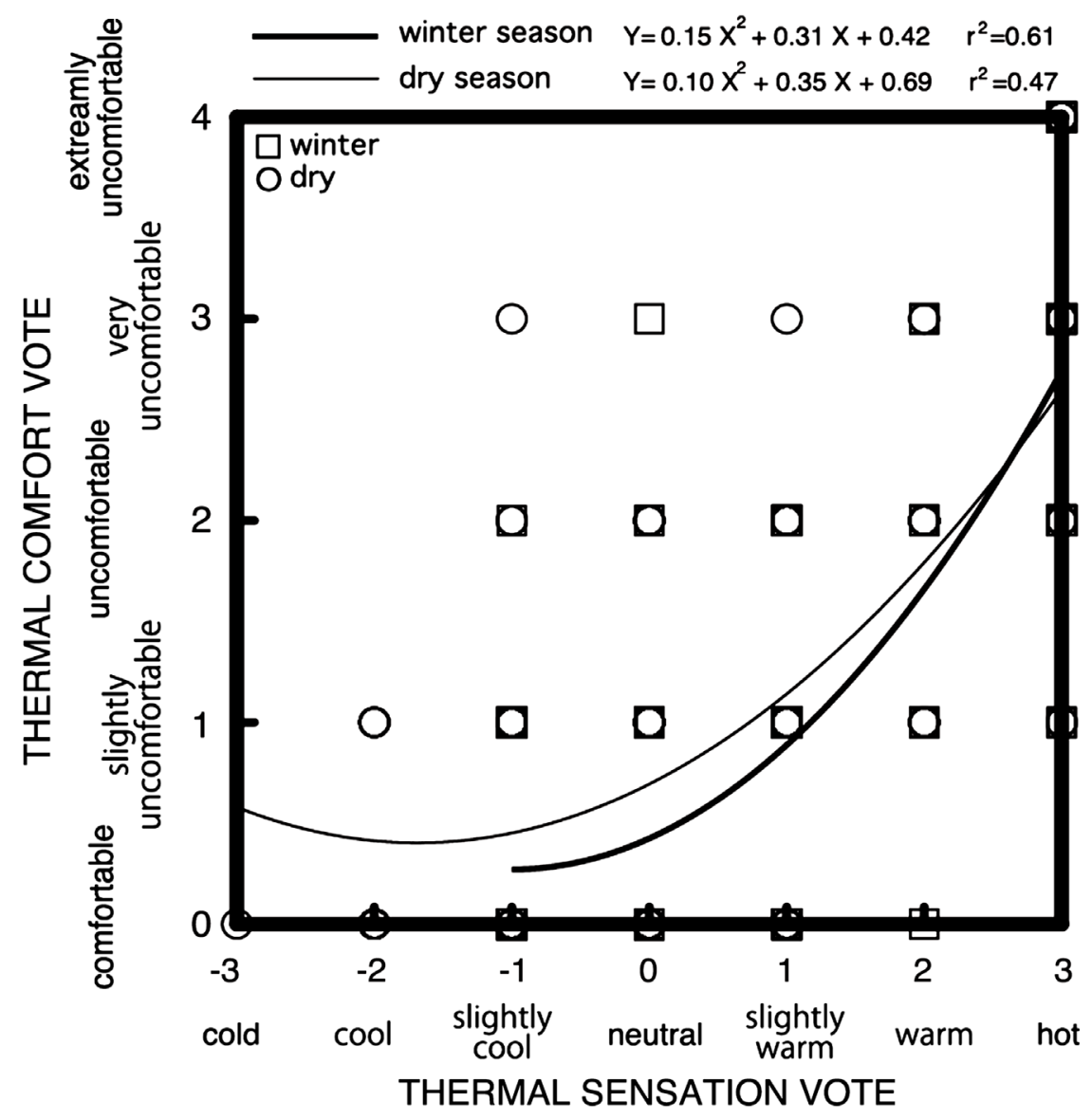

Figure 6. Relation between thermal sensation and thermal comfort. 
There is no noticeable seasonal difference in the intensity of discomfort for thermal comfort when reporting "hot" or "warm" with a strong sensory intensity for heat of thermal sensation. However, when the sensory intensity for heat of thermal sensation weakens from "neutral" to "cold," the degree of discomfort for thermal comfort is reported more strongly in the dry season than in winter.

Focusing on the regression line, thermal sensation reports on thermal comfort reported on the "comfortable" side ranging from "slightly cool" to "neutral," and were -1.75 in the dry season and -1.03 in winter. When the temperature of the $E T F e$ is obtained from the thermal sensation reported value with thermal comfort report (obtained from the regression line) furthest on the "comfortable" side, the ETFe is $30.4^{\circ} \mathrm{C}$ in the dry season and $33.9^{\circ} \mathrm{C}$ in winter. It could be that the tendency to seek warmth is stronger in winter than in the dry season.

We used a nonlinear quadratic regression model to test for equivalence between winter and the dry season. Between winter and the dry season the intercept was $\mathrm{p}<0.10$, thereby showing a significant difference. Therefore, it seems that the effects of seasonal differences appear strongly in the range of ETFe results in this study; their response to thermal comfort for thermal sensation is stronger in winter than in the dry season.

As shown by the relationship between the ETFe and thermal sensation, it was revealed that in winter people tend to prefer a thermal environment about $4{ }^{\circ} \mathrm{C}$ lower than in the dry season. Therefore, at almost the same thermal sensation, the ETFe is lower in winter than in the dry season, and winter may be a more moderate environment than the dry season for thermal environment stimulation of the human body. As described in the relation between the ETFe and thermal sensation, it could be that in winter, when thermal environment stimulation becomes markedly weaker than in the dry season, psychological reactions of the human body can be changed by the effects of other environmental stimuli.

\section{Conclusions}

Effects on thermal sensation of the human body from the outdoor thermal environment of a tropical region with small annual temperature differences were quantified by the total thermal environment evaluation index ETFe of the outdoor environment, and seasonal differences in thermal sensation were compared. The findings obtained in this study are shown below.

1) Even in Bangkok, Thailand, where there are small seasonal differences in the air temperature, it could be that the effects of environmental history appear as seasonal differences.

2) The long-wave thermal radiation by the surface temperature of the building and the ground surface is increased even in the winter tropical urban climate. The effect of blocked sunlight and ground cover is considered to show remarkable results in terms of the thermal psychological response.

3) The ETFe, when people reported a neutral thermal sensation that was neither hot nor cold, was shown to be $29.6^{\circ} \mathrm{C}$ in winter and $33.1^{\circ} \mathrm{C}$ in the dry season. People preferred lower temperatures in winter than in the dry season, and 
tolerated higher temperatures in the dry season than in winter. It seems that the effect of seasonal differences appeared in the amount of change to thermal sensation.

4) It is possible for the human body to experience discomfort due to variations in environmental factors, and this experience can be considered to induce relative comfort. It is thought that one cannot rule out the possibility that people are reporting comprehensive thermal comfort including the effects of space impression, etc. on thermal comfort according to the specific sensation depending on heat exchange. In other words, it seems that the effects of seasonal differences are not likely to greatly affect the amount of thermal sensation change for thermal comfort.

5) There is no noticeable seasonal difference in the intensity of discomfort for thermal comfort, when people reported "hot" or "warm" with a strong sensory strength for the heat of thermal sensation. However, when the feeling intensity for the heat of thermal sensation weakened from "neutral" to "cold," people reported stronger discomfort for thermal comfort in the dry season than in winter. We found in terms of the effect of seasonal difference that people show stronger responses to thermal comfort for thermal sensation in winter than in the dry season.

\section{Acknowledgements}

We would like to express our sincerest gratitude to the study subjects who participated in the present study.

\section{References}

[1] United Nations (2016) Adoption of the Paris Agreement. http://unfccc.int/resource/docs/2015/cop21/eng/109r01.pdf

[2] IPCC Working Group I Contribution to AR5 (2016) Summary for Policymakers of Climate Change 2013: The Physical Science Basis. http://www.climatechange2013.org/images/report/WG1AR5 SPM FINAL.pdf

[3] Shimaoka, A., Machida, K., Kumae, T., Sugawara, K., Kurakake, S., Okamura, N. and Suemune, J. (1987) Seasonal Variation of Basal Metabolism. Japanese Journal of Biometeorology, 24, 3-8.

[4] Fanger, P.O. (1970) Thermal Comfort. Danish Technical Press, Copenhagen.

[5] Ogawa, S., Osada, Y., Kuno, Y. and Yoshida, K. (1975) A Study on the Seasonal Differences of the Thermal Comfort Thermal Conditions. Bulletin of the Institute of Public Health, 24, 222-231.

[6] Tanabe, S. (1990) Thermal Comfort Requirements of Sedentary College-Age Subjects during the Winter Season in Japan. Journal of Home Economics of Japan, 41, 437-445.

[7] Fukai, K., Ito, H., Gotoh, S., Akui, S. and Saito, J. (1993) Experimental Study on Correlation between Standard New Effective Temperature (SET ${ }^{\star}$ ) and Japanese Thermal Sensation: Part 2-Comparison of Thermal Sensation in Winter and Summer Seasons. Transactions of the Society of Heating, Air-Conditioning and Sanitary Engineers of Japan, 51, 139-147.

[8] Tsuzuki, K., Ohnaka, T. and Tochihara, Y. (1998) Seasonal Variation and Age Dif- 
ference in Thermal Responses under Preferred Temperatures Determined by the Mothers. Journal of Home Economics of Japan, 49, 1109-1117.

[9] Kubo, H., Isoda, N. and Yanasa, T. (1994) Seasonal Variations of Air Temperature for Thermal Comfort. Journal of Human and Living Environment, 1, 51-57.

[10] Ishigaki, H., Matsubara, T., Gonda, S. and Horikoshi, T. (2001) Experimental Trial on the Seasonal Differences of the Combined Effect of Air Temperature and $\mathrm{Hu}$ midity on the Human Physiological and Psychological Responses. Journal of Architecture, Planning and Environmental Engineering (Transactions of AI), 543, 49-56. https://doi.org/10.3130/aija.66.49 3

[11] Saioto, T., Kuno, S., Ohno, H., Kida, M. and Nakahara, N. (1992) Seasonal Differences of Physiological and Psychological Responses When Room Temperature Changed from Discomfort to Neutral Conditions. Journal of Architecture, Planning and Environmental Engineering (Transactions of AI), 441, 33-42.

[12] Nonaka, M., Ueno-Towatari, T. and Ohnaka, T. (2009) Differences between Mean and Local Skin Temperatures with Neutral Thermal Sensation and Thermal Comfort-A Comparison of Skin Temperature Differences among Female Students between in Summer and in Winter. Journal of Human and Living Environment, 16, 91-97.

[13] Tochihara, Y., Yamazaki, S., Yoshida, K., Sohn, Y.Y., Isoda, N. and Kobayashi, Y. (1981) Thermal Sensation and Comfort Sensation of Female Inspective Workers in a Printing Factory in Relation to the Thermal Conditions. Japanese Journal of Biometeorology, 18, 92-100.

[14] Iseki, K., Isoda, N., Yanase, T. and Hanaoka, T. (1988) A Survey of Residential Thermal Environments (Part 2) Effect of Thermal Conditions on the Residents. Journal of Home Economics of Japan, 39, 879-884.

[15] Yamazaki, K., Nojiri, K., Sato, Y., Ishibashi, K., Higuchi, S. and Maeda, T. (2006) Effects of Sex, Season and Susceptibility to the Heat and the Cold on Thermoregulatory Responses in Japanese Adults. Journal of Applied Physiology, 11, 21-28.

[16] Yasuoka, A., Kubo, H., Isoda, N. and Kimura, F. (2011) Study on Seasonal Variation of Thermal Comfortable Zone by Psychological and Physiological Response in House. Journal of Envionmental Engineering, 67, 479-484.

https://doi.org/10.3130/aije.76.479

[17] Höppe, P. (2002) Different Aspects of Assessing Indoor and Outdoor Thermal Comfort. Energy and Buildings, 34, 661-665.

https://doi.org/10.1016/S0378-7788(02)00017-8

[18] Nikolopoulou, M. and Steemers, K. (2003) Thermal Comfort and Psychological Adaptation as a Guide for Designing Urban Spaces. Energy and Buildings, 35, 95101. https://doi.org/10.1016/S0378-7788(02)00084-1

[19] Spagnolo, J. and de Dear, R.J. (2003) A Field Study of Thermal Comfort in Outdoor and Semi-Outdoor Environments in Subtropical Sydney Australia. Building and Environment, 38, 721-738. https://doi.org/10.1016/S0360-1323(02)00209-3

[20] Nakano, J. and Tanabe, S. (2004) Thermal Comfort and Adaptation in SemiOutdoor Environments. ASHRAE Transactions, 110, 543-553.

[21] Ahmed, K.S. (2003) Comfort in Urban Spaces: Defining the Boundaries of Outdoor Thermal Comfort for the Tropical Urban Environments. Energy and Buildings, 35, 103-110. https://doi.org/10.1016/S0378-7788(02)00085-3

[22] Oliveira, S. and Andrade, H. (2007) An Initial Assessment of the Bioclimatic Comfort in an Outdoor Public Space in Lisbon. International Journal of Biometeorology, 52, 69-84. https://doi.org/10.1007/s00484-007-0100-0 
[23] Lin, T.P. and Matzarakis, A. (2008) Tourism Climate and Thermal Comfort in Sun Moon Lake, Taiwan. International Journal of Biometeorology, 52, 281-290. https://doi.org/10.1007/s00484-007-0122-7

[24] Cheng, M., Lo, J. and Chen, S. (2011) Investigation of the Effect of Climatic Adaptation on Users' Thermal Comfort Requirement in Outdoor Space. International Journal of the Physical Sciences, 6, 6042-6052.

[25] Kurazumi, Y., Tsuchikawa, T., Kondo, E., Ishii, J., Fukagawa, K., Yamato, Y., Tobita, K., Ando, Y., Matsubara, N. and Horikoshi, T. (2012) Thermal Comfort Zone in Outdoor Environment. Journal of Human and Living Environment, 19, 115-127.

[26] Kurazumi, Y., Ishii, J., Kondo, E., Fukagawa, K., Bolashikov, Z.D., Sakoi, T., Tsuchikawa, T., Matsubara, N. and Horikoshi, T. (2014) The Influence of Outdoor Thermal Environment on Young Japanese Females. International Journal of Biometeorology, 58, 963-974. https://doi.org/10.1007/s00484-013-0681-8

[27] Kurazumi, Y., Fukagawa, K., Yamato, Y., Tobita, K., Kondo, E., Tsuchikawa, T., Horikoshi, T. and Matsubara, N. (2011) Enhanced Conduction-Corrected Modified Effective Temperature as the Outdoor Thermal Environment Evaluation Index upon the Human Body. Building and Environment, 46, 12-21.

https://doi.org/10.1016/j.buildenv.2010.06.012

[28] Kurazumi, Y., Ishii, J., Fukagawa, K. and Aruninta, A. (2015) The Influence of Tropical Urban Climate upon the Human Body. Proceedings of the International Joint-Conference of SENVAR-iNTA-AVAN 2015 (SIA 2015), Johor Bahru, 24-26 November 2015, 105-114.

[29] Kurazumi, Y., Tsuchikawa, T., Matsubara, N., Kondo, E. and Horikoshi, T. (2011) Evaluation of Enhanced Conduction-Corrected Modified Effective Temperature ETFE as the Outdoor Thermal Environment Evaluation Index. Energy and Buildings, 43, 2925-2937. https://doi.org/10.1016/j.enbuild.2011.07.019

[30] Kurazumi, Y., Kondo, E., Ishii, J., Sakoi, T., Fukagawa, K., Bolashikov, Z.D., Tsuchikawa, T., Matsubara, N. and Hori-Koshi, T. (2013) Effect of the Environmental Stimuli upon the Human Body in Winter Outdoor Thermal Environment. Journal of Environmental and Public Health, 2013, 1-10. https://doi.org/10.1155/2013/418742

[31] Nikolopoulou, M. and Lykoudis, S. (2006) Thermal Comfort in Outdoor Urban Spaces: Analysis across Different European Countries. Building and Environment, 41, 1455-1470. https://doi.org/10.1016/j.buildenv.2005.05.031

[32] Humphreys, M. (1976) Field Studies of Thermal Comfort Compared and Applied. Building Services Engineer, 44, 5-27.

[33] de Dear, R.J. and Brager, G.S. (1998) Developing an Adaptive Model of Thermal Comfort and Preference. ASHRAE Transactions, 104, 145-167.

[34] Nikolopoulou, M., Baker, N. and Steemers, K. (2001) Thermal Comfort in Outdoor Urban Spaces: Understanding the Human Parameter. Solar Energy, 70, 227-235. https://doi.org/10.1016/S0038-092X(00)00093-1

[35] Knez, I. and Thorsson, S. (2006) Influence of Culture and Environmental Attitude on Thermal, Emotional and Perceptual Evaluations of a Square. International Journal of Biometeorology, 50, 258-268. https://doi.org/10.1007/s00484-006-0024-0

[36] Kántor, N. and Unger, J. (2011) Benefits and Opportunities of Adopting GIS in Thermal Comfort Studies in Resting Places: An Urban Park as an Example. Landscape and Urban Planning, 98, 36-46. https://doi.org/10.1016/j.landurbplan.2010.07.008

[37] World Medical Association (2016) WMA Declaration of Helsinki-Ethical Prin- 
ciples for Medical Research Involving Human Subjects.

https://www.wma.net/policies-post/wma-declaration-of-helsinki-ethical-principlesfor-medical-research-involving-human-subjects/

[38] Kurazumi, Y., Matsubara, N., Furukawa, N., Fujiwara, M., Ue, A., Ueki, Y., Nagai, H. and Yamamoto, S. (1998) Japanese Weighting Coefficients for Calculating Mean Skin Temperature in Relation to Posture. Japanese Journal of Biometeorology, 35, 121-132.

[39] Kurazumi, Y., Sakoi, T., Tsuchikawa, T., Fukagawa, K., Bolashikov, Z.D. and Horikoshi, T. (2014) Behavioral Thermoregulation Model for Evaluation of Outdoor Thermal Environment. Journal of Ergonomics, 4, 1-14. https://doi.org/10.4172/2165-7556.1000125

[40] Hanada, K., Mihira, K. and Ohhata, K. (1981) Studies on the Thermal Resistance of Women's Underwear. Journal of the Japan Research Association for Textile EndUse, 22, 430-437.

[41] Hanada, K., Mihira, K. and Sato, Y. (1983) Studies on the Thermal Resistance of Men's Underwear. Journal of the Japan Research Association for Textile End-Use, 24, 363-369.

[42] Oliveira, S. and Andrade, H. (2007) An Initial Assessment of the Bioclimatic Comfort in an Outdoor Public Space in Lisbon. International Journal of Biometeorology, 52, 69-84. https://doi.org/10.1007/s00484-007-0100-0

[43] Kurazumi, Y., Ishii, J., Fukagawa, K., Kondo, E. and Aruninta, A. (2016) Ethnic Differences in Thermal Responses between Thai and Japanese Females in Tropical Urban Climate. American Journal of Climate Change, 5, 52-68. https://doi.org/10.4236/ajcc.2016.51007

[44] Kurazumi, Y., Fukagawa, K., Kondo, E. and Sakoi, T. (2014) Effects of Visual Stimuli upon Thermal Sense under Air Conditioning in Summer. Journal of Ergonomics, 4, 1-7.

[45] Fukagawa, K., Kurazumi, Y., Yamato, Y., Tobita, K., Hase, H., Han, S., Oishi, H. and Cao, Z. (2010) The Effect of Visual Stimulus on Thermal Comfort, Analysis of the Visual Factor by Experiment. Proceedings of the 7th International Cost Engineering Council World Congress \& the 14th Pacific Association of Quantity Surveyors Congress, Singapore, 23-27 July 2010, 1-10.

[46] Kurazumi, Y., Tsuchikawa, T., Torii, T., Kakutani, K., Matsubara, N. and Horikoshi, T. (2004) Weighting Coefficients for Calculating Mean Skin Temperature When Considering Convective Heat Transfer Areas. Journal of the Human-Environmental System, 7, 19-28. https://doi.org/10.1618/jhes.7.19

[47] Kurazumi, Y., Horikoshi, T., Tsuchikawa, T. and Matsubara, N. (1994) The Body Surface Area of Japanese. Japanese Journal of Biometeorology, 31, 5-29.

[48] Kurazumi, Y., Tsuchikawa, T., Matsubara, N. and Horikoshi, T. (2008) Effect of Posture on the Heat Transfer Areas of the Human Body. Building and Environment, 43, 1555-1565. https://doi.org/10.1016/j.buildenv.2007.09.001

[49] Miyamoto, S., Horikoshi, T. and Hirokawa, Y. (1998) Projected Area Factors of the Human Body at Standing Posture under Different Clothing Conditions. Journal of Architecture, Planning and Environmental Engineering (Transactions of AIJ), 513, 47-52. https://doi.org/10.3130/aija.63.47 4

[50] Kuwabara, K., Mochida, T., Kondo, M. and Matsunaga, K. (2001) Measurement of Man's Convective Heat Transfer Coefficient by Using a Thermal Manikin in the Middle Wind Velocity Region. Journal of Human and Living Environment, 8, 2732. 
[51] Hendler, E., Crosbie, R. and Hardy, J.D. (1958) Measurement of Heating of the Skin during Exposure to Infrared Radiation. Journal of Applied Physiology, 12, 177-185.

[52] Elam, R., Goodwin, D.W. and Lloyd, W.K. (1963) Optical Properties of the Human Epidermis. Nature, 198, 1001-1002. https://doi.org/10.1038/1981001a0

[53] VDI (2008) VDI 3787-2, Environmental Meteorology-Methods for the Human Biometeorological Evaluation of Climate and Air Quality for Urban and Regional Planning a Regional Level-Part 1: Climate. Beuth, Berlin.

[54] Watanabe, S., Horikoshi, T. and Tomita, A. (2010) Measurement of Solar Radiation Absorptamce of Clothed Human Body in Outdoor. Japanese Journal of Biometeorology, 47, 165-173.

[55] Brager, G.S. and de Dear, R.J. (1998) Thermal Adaptation in the Build Enviroment: A Literture Review. Energy and Buildings, 27, 83-96. https://doi.org/10.1016/S0378-7788(97)00053-4

[56] Kurazumi, Y., Matsubara, N., Tsuchikawa, T., Kondo, E., Ishii, J., Fukagawa, K., Ando, Y., Yamato, Y., Tobita, K. and Horikoshi, T. (2011) Psychological Effects of the Environmental Stimuli on Thermal Sense in Outdoor Spaces. Japanese Journal of Biometeorology, 48, 129-144.

[57] Miura, T. (1968) Studies on the Optimum Temperature on Some Factors Affecting the Shift of Optimum Temperature. The Journal of Science of Labour, 44, 431-453.

[58] Japan Meteorological Agency (2016) ClimatView. http://www.data.jma.go.jp/gmd/cpd/monitor/climatview/frame.php

\section{Submit or recommend next manuscript to SCIRP and we will provide best service for you:}

Accepting pre-submission inquiries through Email, Facebook, LinkedIn, Twitter, etc. A wide selection of journals (inclusive of 9 subjects, more than 200 journals) Providing 24-hour high-quality service User-friendly online submission system Fair and swift peer-review system Efficient typesetting and proofreading procedure Display of the result of downloads and visits, as well as the number of cited articles Maximum dissemination of your research work

Submit your manuscript at: http://papersubmission.scirp.org/

Or contact health@scirp.org 